\title{
TERRITÓRIO: POSSIBILIDADES DE PESQUISA NA GEOGRAFIA AGRÁRIA
}

\author{
Edson Batista da Silva ${ }^{1}$ \\ Sebastião Rafael Gontijo²
}

\begin{abstract}
Resumo: Este artigo discute as possibilidades que a categoria território oferece para as pesquisas em Geografia Agrária. Para tanto, foram utilizadas pesquisa bibliográfica com localização, levantamento, leitura e fichamento de referências que discorrem sobre a categoria território. Além de pesquisa de campo, especificamente no povo indígena Karajá, com observação sistemática, registro fotográfico e coleta de depoimentos. Há uma polissemia de concepções, é necessário o debate continuo para evitar o uso descuidado da categoria. Na geografia agrária, especificamente em temas como luta pela terra e pela reforma agrária, lutas das populações originárias, disputa de perspectivas de produção no campo, a categoria território oferece instrumentos importantes para análise da realidade material. Nesse sentido, o povo indígena Karajá, no campo de forças com os agentes do colonialismo e da colonialidade do poder, sofrem a redução do seu território originário pelas atividades pecuárias, turísticas e provenientes da especulação imobiliária urbana.
\end{abstract}

Palavras-chave: Território; Campesinato; Geografia Agrária; Povo Karajá.

\section{TERRITORY: RESEARCH POSSIBILITIES IN AGRARIAN GEOGRAPHY}

\begin{abstract}
This paper discusses the possibilities that the territory category offers for research in Agrarian Geography. For this purpose, we used bibliographical research with localization, survey, reading and annotations of references that expatiate on the territory category. Besides field research, specifically on the Karajá indigenous people, with systematic observation, photographic record and testimony collection. There is a polysemy of conceptions, it is necessary the continuous debate to avoid the careless use of the category. In agrarian geography, specifically in themes such as the struggle for land and agrarian reform, struggles of the native populations, disputes over perspectives of production in the countryside, the territory category offers important tools for analysis of the material reality. In this sense, the Karajá indigenous people, in the field of forces with the agents of the colonialism and the coloniality of power, suffer the reduction of their original territory by the livestock, tourist activities and coming from the urban real estate speculation.
\end{abstract}

Keywords: Territory; Peasantry; Agrarian Geography; Karajá People.

\footnotetext{
${ }^{1}$ Docente da Universidade Estadual de Goiás (UEG). edson_bat_silva@hotmail.com

${ }^{2}$ Universidade Federal de Goiás (UFG). tiao.lobo@ hotmail.com

Estudos Geográficos, Rio Claro, 17: 56-77, jan./jun. $2019 \quad$ (ISSN 1678-698X)
}

http://www.periodicos.rc.biblioteca.unesp.br/index.php/estgeo 


\section{INTRODUÇÃO}

Esse artigo é resultado do $\mathrm{V}$ Circuito da Sociobiodiversidade, que teve como tema: "Território, Alimento e Questão Indígena", realizado nas cidades de Goiás e Aruanã-GO, de 11 a 15 de Fevereiro de 2019. O seminário compôs as atividades do projeto: "Sociobiodiversidade e Desenvolvimento Territorial: perspectivas para o Mundo do Cerrado (PGPSE-CAPES)." Contou com a participação de estudantes de Pós-Graduação do Instituto de Estudos Socioambientais-IESA/UFG, de docentes da Universidade Estadual de Goiás-UEG, Universidade Federal do Tocantins-UFT, Universidade Paulista Júlio de Mesquita Filho-UNESP, Universidade Federal da Paraíba-UFPB, Universidade de São Paulo-USP e Instituto Federal Goiano-IFG.

Na Geografia pós-1970 o território assumiu centralidade como categoria de análise. Na década de 1990 tornou-se conceito quase que obrigatório nos projetos de pesquisa submetidos as agências de fomento nacionais e internacionais. A categoria em questão edificou-se uma agenda de pesquisa, tornou-se o centro do discurso geográfico. O uso descuidado, exagerado, pouco atento tem produzido sua banalização. O território explica tudo, contraditoriamente, não explica nada. $\mathrm{Na}$ Geografia, especificamente na geografia agrária há inúmeros entendimentos. Mas até que ponto essas definições oferecem elementos que explicam os problemas do campo brasileiro? Os entendimentos elaborados, sobretudo na geografia agrária são desprendidos de equívocos e contradições?

O objetivo do texto foi discutir as possibilidades que a categoria território oferece para as pesquisas em Geografia Agrária. Para tanto, foram utilizadas pesquisa bibliográfica com localização, levantamento, leitura e fichamento de referências que discorrem sobre a categoria território. Além de pesquisa de campo, especificamente no povo indígena Karajá, com realização de observação sistemática, registro fotográfico e coleta de depoimentos. Os nomes dos entrevistados mencionados são verdadeiros, visto que obtivemos autorização dos mesmos.

Os resultados incluem também nossas atividades como docentes da Universidade Estadual de Goiás, tanto com orientações de trabalhos de pesquisa de conclusão de curso, projetos de pesquisa, extensão, quanto com de trabalhos de campo realizados. O artigo divide-se em três partes; na primeira discutimos compreensões de território na Geografia e possibilidades de uso na geografia agrária, na segunda parte abordamos entendimentos do conceito na geografia agrária, com apontamento das nossas discordâncias e concordâncias relativas a tais definições, na terceira a discussão verte-se para o povo indígena Karajá, sua luta para permanência no território originário em Aruanã-GO. No próximo item o debate circunscreve a conceituações de território na Geografia.

\section{O TERRITÓRIO NA GEOGRAFIA: USOS E POSSIBILIDADES NA GEOGRAFIA AGRÁRIA}

Segundo Silva (2013), a palavra território é originaria do latim, associado à terra. Na geografia, foi entendida como extensão de terra, área sob controle do Estado. Também foi pensada como espaço material sob domínio de grupos sociais e suas instituições correlatas. Ratzel (1988), um clássico no debate, afirmou a sua condição ontológica. Os grupos humanos mais simples não podem ser concebidos

Estudos Geográficos, Rio Claro, 17: 56-77, jan./jun. 2019 (ISSN 1678-698X) http://www.periodicos.rc.biblioteca.unesp.br/index.php/estgeo 
sem território, perdê-lo significa decadência, pois é fundamental para as necessidades vitais.

O Estado surge pela necessidade de defendê-lo e ampliá-lo devido ao crescimento populacional. Costa (2008) declara que Ratzel, pelo seu pensamento conservador e autoritário, concebeu o Estado como entidade moral e espiritual. Gottmann (2012) refutou a concepção das leis naturais de crescimento dos Estados, mas aderiu à compreensão do território como espaço de governança, entre outros conceitos de Ratzel.

$\mathrm{Na}$ discussão de soberania, por meio das noções de isolamento e cosmopolitismo, o autor afirmou o aprofundamento do território como espaço de oportunidade, em detrimento a local de segurança. Silva (2013) menciona a possível superação do Estado territorial, tanto pela contestação de sua soberania, quanto pela perda de capacidade de proteção dos grupos sociais. Conforme destaca a autora, há méritos nas críticas a Ratzel, mas existem fragilidades quando reduz sua teoria à mera ideologia.

De fato há em Ratzel (1988 e 1990) influências do romantismo, do malthusianismo, da questão nacional alemã, além do evolucionismo e do positivismo. Nele, o território é entendido na dimensão material e como espaço de governança. Essas constatações não eliminam o mérito de ter defendido a legitimidade da Geografia no conjunto das ciências humanas, por meio da condição ontológica do território. Não obstante, essa ontologia se coloca para o campesinato e para os povos indígenas? Ratzel (1988) assevera que a família é o exemplo mais simples de relação político/econômica com a terra; a dimensão do território é dada pelo tamanho da família.

Chayanov (1974) entende que a propriedade camponesa é determinada pelo tamanho do grupo familiar, assentada na relação trabalhador/consumidor. Marx (2010) adverte que o ser humano é também ser natural, munido de forças vitais, mas dependente dos objetos independentes dele. $O$ controle mínimo da natureza inorgânica permite satisfazer carências vitais. Esses autores partem de pressupostos e questões diferentes. Mas ambos afirmam a importância do controle do estrato natural pelos grupos humanos, para sua existência, para a reprodução social da família camponesa, para saciar carências vitais.

Há nisto uma dimensão ontológica do território; Sem o controle mínimo do substrato espacial material, da terra, o camponês, os povos indígenas torna-se virtualidade, imaterialidade, tanto no sentido político/econômico quanto no cultural. Existe uma imagem desejada do espaço material, com as formas de uso, de apropriação, de domínio, de tessitura dos limites, de arranjo e configuração espacial, mas sem a terra isso permanece como potencialidade. A permanência, a conquista da terra impulsiona sua materialização. A ontologia do território é um pressuposto importante para os estudos em Geografia agrária, sobretudo de temas como a luta dos povos indígenas pelo território originário, ou dos camponeses pela terra e pela reforma agrária. A imaterialidade necessita do substrato espacial material para concretizar-se.

Mas a (i)materialidade do território é determinada pela disputa entre sujeitos. Para tanto Raffestin (1993) propõe a analise relacional na abordagem territorial. Conforme o autor, as organizações travam relações simétricas e dissimétricas, multidimensionais (econômicas, políticas, culturais). Todas relações envolvem poder, tecida por organizações e atores, que vão do indivíduo ao Estado. Raffestin (1993, p.07), define território nos seguintes termos: "O território [...] não poderia ser

Estudos Geográficos, Rio Claro, 17: 56-77, jan./jun. 2019 (ISSN 1678-698X) http://www.periodicos.rc.biblioteca.unesp.br/index.php/estgeo 
Território: possibilidades de pesquisa...

mais nada que o produto dos atores sociais. São esses atores que produzem o território." Em outro momento acrescenta:

[...] é o resultado de uma ação conduzida por um ator sintagmático (ator que realiza um programa) em qualquer nível. Ao se apropriar de um espaço, concreta ou abstratamente [...]. O território, nessa perspectiva, é um espaço onde se projetou um trabalho, seja energia e informação, e que, por consequência, revela relações marcadas pelo poder. O espaço é a prisão original, o território é a prisão que os homens constroem para si (RAFFESTIN 1993, p. 128).

A despeito da menção ao trabalho, com cisão do labor manual/mental e das relações de poder envolvidas na distribuição desigual dos recursos produzidos, Raffestin (1993) coloca o ator no centro de sua elaboração teórica. Para ele, há atores sintagmáticos, portadores de um programa, e os paradigmáticos, sem projetos prévios elaborados. Nesse ponto, o autor utiliza o termo de forma oposta à Escola Acionalista e de Chicago. Wautier (2001) adverte que o ator é o participante ativo nas mudanças sociais.

Mas também foi concebido como executor de funções numa sociedade moralmente organizada. O desenvolvimento capitalista descolou 0 ator de suas amarras capitalistas, cindiu ator e sistema. Na sociologia, tornou-se preponderante o ator crítico, autônomo, resistente, membro dos movimentos sociais, em detrimento do ator estático da sociedade capitalista. Vasconcellos (2013) afirma que a Escola Acionalista, proposta por Touraine, defendeu os atores sociais como sujeitos da história, formuladores de projetos de classe. $O$ ator atuaria conforme os princípios da identidade, com auto/reconhecimento, oposição e definição do inimigo, com desejo de dominação.

Wautier (2001) descreve que Touraine o denominou ator-sujeito. Segundo a autora, há equívocos nessa junção, porque sujeitos são construções, disposições, liberdade e negação, luta pela existência, pela individuação/subjetivação. Raffestin (1993) usa o termo ator paradigmático próximo à concepção de ator estático. Questionamos se nesse momento a concepção de ator paradigmático não estaria próximo a elaboração durkheimiana? E o ator sintagmático, não o aproximaria do ator racional weberiano, agente de escolhas racionais? Se essa tese é correta, esse ator pode ser sujeitos/grupos resistentes, como também sujeitos/grupos conservadores, reacionários, não somente atores críticos, autônomos, resistentes ao sistema capitalista.

Wautier (2001) acrescenta que os sujeitos se tornam atores. Perguntamos uma vez mais, haveria um viés weberiano do ator sintagmático que conflita com a concepção de classe? Categoria relevante nos estudos em Geografia agrária. Nós entendemos que os camponeses ou os grupos indígenas nem sempre agem conforme performances pré-definidas. Também não são apenas atores racionais, em muitas situações são conduzidos por grupos externos, tornam-se objeto de mando e manipulação. Do mesmo modo, são razão e emoção, portam subjetividade rebelde.

Por isso, nós entendemos os camponeses e os grupos indígenas, em inúmeras situações como classe, composta por sujeitos resistentes, que negam a ordem hegemônica e lutam pela existência, estão a contrapelo. Escolhemos analisar a disputa territorial fundamentada na relação de poder essencial na sociedade capitalista, a luta de classes. Contudo, isso não implica a depreciação de Raffestin

Estudos Geográficos, Rio Claro, 17: 56-77, jan./jun. 2019 (ISSN 1678-698X) http://www.periodicos.rc.biblioteca.unesp.br/index.php/estgeo 
(1993). Sua teoria suscitou questões importantes, desestatizou o poder, propôs o viés relacional, defendeu o poder imanente a todas relações, o que viabilizou estudos sobre disputas entre grupos sociais diversos. Também demonstrou as manifestações do poder por meio dos discursos, da violência direta, da religião, da língua, das normas e regras etc.

Também afirmou no estudo do território a relevância das estratégias, dos mediatos, como o dinheiro, o discurso e o trabalho. Além disso, na disputa territorial, preconizou a análise dos códigos e das diferenças espaço/tempo. Mas isso não quer dizer que deve-se adotar os construtos teórico-metodológicos do autor sem posicionamento crítico. Saquet (2011 \& 2015) retoma o geógrafo em questão, na elaboração de uma geografia das temporalidades e das territorialidades. Segundo Saquet (2011 \& 2015), as temporalidades lentas podem construir um desenvolvimento com mais autonomia. Assertiva importante, por exemplo, para estudos que envolvem o debate da agroecologia.

Outra contribuição é a concepção de território-rede. Raffestin (1993) mencionou sua constituição pelas redes de circulação e comunicação. Haesbaert (2009) acrescenta que os territórios se fazem no e pelo movimento, são descontínuos, reticulares, sobrepostos. Assim sendo, a rede como componente do território permite conexões, movimentos, fluxos, e controle do movimento. $O$ território-rede promove o controle de fluxos, polos de conexão, senhas, pontos de acessibilidade, canais, dutos, emissores e receptores. Segundo o autor, as redes dos agentes capitalistas desordenam os territórios dos grupos subalternizados.

Nos estudos em Geografia Agrária, principalmente relacionados a mundialização da agricultura e o campesinato, ou as populações originárias, o controle de ferrovias, silos, portos, hidrovias propicia às corporações a formação de estoques de mercadorias. Isso ocasiona o controle do mercado de alimentos pelo domínio do movimento, a escassez produzida comporta a reprodução ampliada do capital. Do mesmo modo, expulsa comunidades camponesas e populações originárias de seus espaços históricos. Mas Saquet (2015) adverte que existem territórios-redes na pequena escala, tecidos por sujeitos explorados. Advertência importante, mas na Geografia Agrária devemos também observar territórios-redes na macroescala, como o tecido pelo campo de forças entre os agentes do agronegócio e da Via Campesina. As alianças, pactos e coalizões de classe criam disputas pela produção do espaço.

Além disso, Raffestin (1993) propugnou o estudo dos atores matéria/técnica e técnica/matéria. No que tange à terra, afirmou tratar-se de uma matéria finita, objeto de disputas territoriais. Contudo, a terra é sobretudo um meio de produção. Entretanto, há outros pontos débeis em Raffestin (1993). O mais relevante é a concepção de espaço anterior ao território, enquanto matéria-prima. A anulação do espaço implica confusão entre produção do território e produção do espaço. Para evitar equívocos, entende-se o território como uma dimensão do espaço, refere-se à análise das relações de poder que permeiam o espaço.

Entende-se que o elemento fundante do território não é a materialidade em si, uma vez que essa reflete, espacializa uma disputa, mas não é a própria disputa, essa é tecida por sujeitos, classes, não pelas formas espaciais. Considerá-lo apenas sob este viés incorre-se no risco de cristalização, de imobilização, que elimina a dinâmica posta na sua constituição. Nesse contexto, o espaço é concebido como produção social relacional (HARVEY 2014b, SMITH, 1988).

Estudos Geográficos, Rio Claro, 17: 56-77, jan./jun. $2019 \quad$ (ISSN 1678-698X) http://www.periodicos.rc.biblioteca.unesp.br/index.php/estgeo 
As relações de poder promovem arranjos, ordenações, usos, apropriações, em suma, uma produção específica do espaço. Como adverte o próprio Raffestin (1993), os limites não são inocentes. Os sujeitos disputam a disposição dos nós, das linhas e redes, que conforma uma malha favorável à determinada classe. A produção do espaço é (i)material, envolve uma imagem desejada, fruto de intencionalidades dos agentes capitalistas, dos projetos contra hegemônicos, das experiências sócio históricas das classes sociais. Há uma geografia do agronegócio contraposta a geografia do campesinato. Esses projetam, realizam geo-grafias diferentes, antagônicas.

Por isso há disputas na disposição dos fixos: Como será utilizado o espaço, com divisões, interdependências e arranjos? Essas questões são objeto de disputa porque delimita a ação, permite uma operacionalidade específica do poder. A propriedade camponesa implica arranjo, ordenação específica de usos, limites que conflitam com a propriedade sob o comando do agronegócio. A policultura, as subdivisões casa-quintal, as instalações (chiqueiro, paiol, curral, indústria doméstica, etc.), as combinações horta-curral, quintal-curral, policultura-criações, todas essas ações conformam uma paisagem, interdependências da geografia específica do campesinato, elemento que deveria ser objeto maior de atenção nos estudos em geografia agrária.

No Brasil, a concepção de Raffestin (1993) obteve notória aceitação. Saquet (2011 \& 2015), na sua abordagem histórico/crítica, relacional, reticular, pluridimensional, (i)material e operativa politicamente, vale-se de Dematteis, Raffestin, Brunet e dos entendimentos obtidos nas suas pesquisas. Ele propõe a operacionalização do conceito, defende a explicação da rede local de sujeitos, dessa em conexão com as redes extralocais e a caracterização do "meio." Sugere a observação do ator e seu programa, do trabalho humano, dos mediadores materiais, além das vinte e cinco leis mencionadas por Brunet na produção do território, tais como: apropriação, intercomunicação, delimitação, dentre outras.

Segundo ele, os territórios são múltiplos, sobrepostos, heterogêneos, históricos, relacionais, resultantes da relação sociedade/natureza, das territorialidades dos grupos sociais inseridos em relações espaço/tempo (SAQUET, 2011 \& 2015). Em outro momento, adiciona que os territórios são produtos das relações de poder dos grupos e classes sociais. Trata-se de espaços de mobilização, organização, luta e resistência política. Assim como refere-se à normatização, regulação, apropriação, uso e dominação envolvida na produção do espaço. No seu estudo, merece atenção o tempo histórico e as coexistências, as transterritorialidades, as transmultiescalaridades e as transtemporalidades.

Saquet (2011 \& 2015) preocupa-se com a distinção entre espaço e território. Compreende o território como resultado das relações de poder pluridimensionais, da dinâmica territorial, da construção histórica dos sujeitos portadores de identidades. Os territórios resultam da construção histórica do e no espaço. Também recomenda o seu estudo conectado às categorias lugar, paisagem, espaço e tempo. Conforme o autor, sua proposta visa projetos de transformação, de sustentabilidade e governabilidade coletiva, com vistas à autonomia. Portanto, concebe o conceito nos seguintes termos:

O território é sucintamente, produto e condição das relações sociedade/natureza, pluridimensional,

com objetivações/formas/relações sociais e subjetivações/significados econômicos, políticos e culturais, contendo componentes fixos (naturais e construídos socialmente), redes e fluxos (produção-

Estudos Geográficos, Rio Claro, 17: 56-77, jan./jun. 2019 (ISSN 1678-698X) http://www.periodicos.rc.biblioteca.unesp.br/index.php/estgeo 
distribuição-circulação-troca-consumo), juntamente com o movimento da natureza (SAQUET, 2015, p. 87).

Saquet (2011 \& 2015) retoma Ratzel, ao defender a condição ontológica do território. Também o torna sinônimo de estrato material e imaterial concomitantemente. Ele utiliza indistintamente, de forma arriscada, os termos sujeito e ator, reconhece as relações de poder, mas não situa a classe como fundante na disputa territorial. Sua definição é resultado de certo ecletismo, com aportes marxistas, estruturalistas e anarquistas. Seu conceito é amplo, com uma miríade de adjetivações, o que o torna confuso e pouco claro em determinados momentos. Nesse ínterim, o autor preocupa-se em distinguir espaço e território, mas em muitas situações tal diferença é pouco clara: "As estradas estão no seio da formação e gestão do território [...] (SAQUET, 2015, p. 116)."

Não seria isso exemplo de formação do espaço? Nota-se que, na geografia contemporânea brasileira há o anseio de tornar território a categoria substancial da explicação geográfica, com isso, há o risco de banalização, diante da possibilidade de o território explicar o tudo e o nada, perdendo assim a sua especificidade. A operacionalidade dessa categoria em Saquet (2011 \& 2015), a despeito do anseio do autor, esbarra num conceito amplo e generalista, que impõe o uso de um arsenal de elementos. Ele propõe vinte e oito aspectos para sua abordagem territorial histórico-crítica, relacional. Certamente a aplicação dessa proposta enfrenta desafios de operacionalização, dado a magnitude dos elementos propostos para a análise.

No nosso entendimento é louvável o esforço do autor, mas a proposta em questão necessita de refinamento, de escolha dos aspectos que realmente são essenciais numa abordagem territorial. Mas há autores brasileiros que buscam outros aportes teórico-metodológicos. Haesbaert (2009) não se atém a Raffestin, ou à extensa literatura italiana mencionada por Saquet (2011 \& 2015), mas a Gilles Deleuze, Felix Guatarri e Henri Lefebvre. O autor defende uma concepção integradora, que conecta a materialidade e a idealidade. Segundo ele, o território representa o conjunto das experiências humanas, com domínio e apropriação no/com o espaço.

O autor concebe o território como a interação do poder político, simbólico, econômico e jurídico-político. De modo sucinto, ele acredita que o território é a mediação espacial do poder. $\mathrm{Na}$ abordagem territorial, recomenda atenção com as relações interescalares multidimensionais e com a diferença entre domínio e apropriação. O domínio reporta à transformação da natureza pela técnica, a apropriação remete à dimensão simbólica no controle do espaço. Nas palavras do autor: "Território só poderia ser concebido através de uma perspectiva integradora entre as diferentes dimensões espaciais (e da sociedade com a própria natureza) (HAESBAERT, 2009, p. 74)." Em outro momento esclarece:

Fica evidente neste ponto a necessidade de uma visão de território, [...], como um hibrido - hibrido entre a sociedade e natureza, entre política, economia e cultura, e entre materialidade e idealidade, numa complexa interação espaço-tempo[...]. [...] o território pode ser concebido a partir da imbricação de múltiplas relações de poder, do poder mais material das relações econômico-políticas ao poder mais simbólico das relações de ordem mais estritamente cultural. (HAESBAERT, 2009, p. 79).

Estudos Geográficos, Rio Claro, 17: 56-77, jan./jun. 2019 (ISSN 1678-698X) http://www.periodicos.rc.biblioteca.unesp.br/index.php/estgeo 
O autor busca solucionar a dicotomia materialidade/idealidade, por isso elabora um conceito generalista. Também retoma a ontologia do território proposta por Ratzel, expresso no título do livro: "O mito da desterritorialização." Assim sendo, tal como o autor clássico, defende a impossibilidade de existência humana despida do controle de porções mínimas do espaço. Na operacionalização da sua proposta, especificamente na discussão dos "aglomerados de exclusão" se detém na dimensão político-econômica.

Da mesma forma, no debate da multiterritorialidade, entendida enquanto possibilidade de os sujeitos, grupos sociais percorrerem, experimentarem, reconstruírem, conectarem-se, acessarem múltiplos territórios, pela mobilidade concreta e virtual, o viés econômico assume preponderância em relação ao cultural. Haesbaert (2009) reconhece que viver, experienciar múltiplos territórios é negado aos sem-teto, sem-comida, sem-terra, aos sobrantes e explorados pelo capitalismo espoliador. Não obstante, o autor oferece elementos para pesquisas em Geografia Agrária, sobretudo relacionadas ao estudo das identidades territoriais camponesas.

Silva (2013) também parte de outro pressuposto, o filósofo Castoriadis e sua concepção de imaginário e imaginação como ontologia criadora humana. A autora propõe o território como significação imaginária social. O território é uma criação da sociedade, formado por significações imaginárias, como: o Estado, o poder e a soberania. Nessa abordagem, o substrato natural não é determinante, o território não é sinônimo de espaço vital, ou produto da arte de governar. Mas uma forma social/histórica, uma imagem ideal instituída pela sociedade, em que participam as mentalidades e ideologias. A autora propõe que o território, sinônimo de estrato natural, escamoteia os sujeitos sociais e seus processos políticos. Ela se contrapõe à determinação do ser social e da história, defende a indeterminação e a criação como instituintes da sociedade.

Essa concepção destoa das elaborações correntes, apresenta significativa inovação. Mas necessita tornar-se ferramenta na leitura da realidade, sob o risco de recair na abstração e idealização. A proposta de análise da autora deve ser observada em estudos de Geografia Agrária, possui potência de análise. 0 entendimento do território como significação imaginária social pode levar-nos a entender como camponeses, quilombolas, povos indígenas construíram formas sociais, históricas, imagens ideais e idealizadas de gestão do poder que escapam das criações do Estado moderno.

Santos (1994), pelo contrário, num viés iminentemente materialista, sugere a compreensão do território pelo seu uso, quadro da vida cotidiana. Conforme o autor, trata-se de uma forma impura, hibrida, sinônimo de espaço humano, habitado, formado por objetos e ações, por lugares contíguos e por redes. O autor indica no estudo do território atenção às horizontalidades, as verticalidades, ao acontecer homólogo, complementar e hierárquico. Também defende a transnacionalização do território, com a interdependência mundial. Para ele, as redes instalam o mercado universal, a democracia de mercado e o neoliberalismo. Isso produz a dialética do território e no território, o território habitado reage pelo acontecer solidário ao território hegemônico.

Essa abordagem anula a especificidade do território, o associa à definição de espaço como sistema de objetos, sistemas de ações (SANTOS, 1996). A disputa entre território habitado e território hegemônico, a despeito da coisificação, coloca em cena a luta entre classes. Outra compreensão materialista é dada por Gomes (2008, p 38): "o território é a forma espacial instrumentalizada como forma de poder,

Estudos Geográficos, Rio Claro, 17: 56-77, jan./jun. 2019 (ISSN 1678-698X) http://www.periodicos.rc.biblioteca.unesp.br/index.php/estgeo 
pelo domínio sobre a distribuição ou simplesmente pelo controle dos objetos especializados." Gomes (1997), também compreende que a reprodução da vida social imersa no espaço faz com que o poder crie um arranjo espacial. O controle de acesso e as contribuições de Foucault (1979) são caras a essa definição. O domínio das formas não representa o comando imediato dos sujeitos.

Os territórios se fazem e se desfazem sem que as formas sejam totalmente reconstruídas. É lúcido conceber a ontologia do espaço, mas são as disputas de poder, não o poder em si, que imprime novos arranjos espaciais. De modo antagônico, Bonnemaison (2002) apresenta o território na dimensão simbólicoidealista, sem ignorar o viés materialista. Para o autor, o território é um conjunto de lugares hierarquizados, conectados por itinerários, envolve enraizamento, relação afetiva com a terra. A questão de fundo é o estudo da cultura, especificamente dos grupos étnicos "tradicionais." O território é produto étnico/cultural, expressa visão de mundo, subjetividade, alteridade, convivência. Também empiriza geossímbolos e permite enraizamento.

Segundo Bonnemaison (2002), a relação dos homens com a terra engendra territórios, e nessa elaboração, a subjetividade é essencial. A construção de hierarquias, itinerários, enraizamentos, afetividades, convivências são atos subjetivos humanos. A disputa territorial não é o essencial, mas a materialização da subjetividade exteriorizada nos geossímbolos, que demarca territórios étnicos. É importante tal entendimento, principalmente no estudo de grupos étnicos, como as pesquisas vinculadas aos povos indígenas. No entanto, há o risco de sobrestimar a cultura, com a explicação culturalista da realidade.

Bañuelos e Bórquez et. al (2015), do mesmo modo, tomam a compreensão de território dos grupos originários da América. O território, concebido pelas relações intersubjetivas sujeito/sujeito, compõe os corpos humanos, detém vida, é o adjetivo da terra. Segundo os autores, na cosmovisão indígena, é formado por três espaços; o espaço celeste, dos vivos e dos mortos. Território significa em suma um sujeito que contém vidas. A acumulação primitiva produziu a subsunção formal e real do território, portanto, destruiu o território como sujeito e o tornou parte do corpo do capital.

Tal compreensão contém pressupostos decoloniais, é coerente com a percepção dos grupos originários, com a defesa de seus territórios e estudos que os consideram na disputa com o capital. Não obstante, oferece poucos elementos à abordagens que tomam como centro a disputa territorial travada pelo campesinato, em detrimento dos grupos originários indígenas. Os camponeses no Brasil e em Goiás não são campesíndios, denominação adequada para países como México, Bolívia, Peru, etc. Souza (2007), pelo contrário, propõe outra definição de território.

Oposto a Raffestin (1993) e Ratzel (1988 \& 1990), os quais acusam de coisificar, tornar território sinônimo de espaço social, assevera: "[...] o território não é o substrato, o espaço social em si, mas sim um campo de forças, as relações de poder espacialmente delimitadas e operando, destarte, sobre um substrato referencial (SOUZA, 2007, p. 97)." Do mesmo modo, acrescenta que território não é sinônimo de espaço geográfico, porção qualquer da superfície da terra. Essa associação com o substrato espacial material, com rios, matas e cadeias de montanhas cria hipostasiamento.

Haesbaert (2004), adverte Souza (2007, 2013), entende que ele incorre no risco de sociologizar o território, desgeografizá-lo. A base social/geográfica é indispensável para realização das relações sociais, o meio porta virtudes difíceis de

Estudos Geográficos, Rio Claro, 17: 56-77, jan./jun. 2019 (ISSN 1678-698X) http://www.periodicos.rc.biblioteca.unesp.br/index.php/estgeo 
serem encontradas e traduzidas em parâmetros conceituais. Concorda-se que na construção de conceitos, na análise do real, se impõe a atenção à realidade prático/sensorial (MARX (1845]1999). Da mesma forma que se dá com a observação da relação teoria prática. Nesse ínterim, o trabalho é ontológico à condição humana, significa criação do próprio homem (ENGELS, 1876).

Por meio do trabalho, o ser humano age e conhece, conhece e atua. Os sujeitos tornam-se resultado da sua realidade social/histórica. Esse pressuposto adverte que o substrato material não é somente referência como determina Souza (2007 \& 2013). É produto social que produz os sujeitos concomitantemente. A consciência torna-se produto sociohistórico, resultado da interdependência entre infraestrutura e superestrutura (MARX, [1945] 1999). Se o ser humano é corolário de tipos de sociedade, nas disputas territoriais as relações de poder envolvem imagens dos arranjos, das ordenações desejadas do espaço.

Os sujeitos em disputa trazem consigo uma imagem desejada. O substrato não é somente referência, é parte constituinte dos sujeitos sociais. Os camponeses, por exemplo, lutam não somente por um substrato referencial, mas por um espaço de reprodução social característico. Eles carregam consigo o desejo de formação do sítio, com um arranjo espacial específico, enquanto as lideranças dos movimentos sociais lutam e anseiam pela construção da propriedade coletiva. Mas Souza (2013) não ignora a materialidade, reconhece a dimensão espacial material do território, que permite entrever quem domina quem no espaço produzido. A preocupação dele é não tornar o território símbolo somente de coisa material, o que anula a dialética.

O que ele ignora é que, no campo de forças, a materialidade está embrenhada nas concepções, nas visões de mundo, nas experiências dos sujeitos sociais e na própria disputa territorial. Portanto, a materialidade compõe os sujeitos. Por isso, menciona mas não aprofunda a importância dos trunfos espaciais. $O$ domínio precário de porções do espaço fortalece os sujeitos rebelados. Como mencionado, Wolf (1972) aponta que os camponeses detentores de terras promovem a produção de autoconsumo, o que representa tenacidade nas disputas territoriais. Mas é fato que o território existe a partir da disputa entre sujeitos, entra as classes sociais.

Formas pretéritas desabitadas são o resultado de campo de forças do passado, que imprimiu uma dada organização ao espaço. Mas despovoadas não são mais território, no entanto, permitem analisar possíveis embates responsáveis por sua produção. Logo, disputa territorial significa embate pela conquista e produção do espaço. Essa assertiva parece banal, mas na Geografia e especificamente na geografia agrária há uma polissemia de territórios. No próximo tópico discorremos especificamente sobre essa questão.

\section{O TERRITÓRIO NA GEOGRAFIA}

Na geografia agrária, Fernandes (1999 e 2008b) menciona territórios quilombolas, camponeses e territórios das multinacionais. $\mathrm{Na}$ elaboração do conceito, afirma que o espaço é um a priori e o território um a posteriori, o que reafirma o endosso a concepção de Raffestin (1993). Fernandes (2005, 2008a \& $2008 b)$ tem como estofo a construção de uma teoria geográfica dos movimentos sociais, o qual denomina de movimentos socioterritoriais, além da elaboração dos paradigmas da questão agrária e do capitalismo agrário. Sua análise aponta a

Estudos Geográficos, Rio Claro, 17: 56-77, jan./jun. 2019 (ISSN 1678-698X) http://www.periodicos.rc.biblioteca.unesp.br/index.php/estgeo 
insuficiência do território como espaço de governança e propõe uma tipologia para seu estudo.

Concebe os territórios governança, propriedade, relacionais e imateriais. Silva (2013) afirma que Fernandes constrói combinações, conjuntos, intersecções próximas à lógica conjuntista-identitária, em que o substrato material é expressivo. $\mathrm{Na}$ exposição dessa tipologia, Fernandes (2008b) propõe o território-governança como aquele que comporta os territórios do Estado. O território propriedade se circunscreve à propriedade capitalista e não capitalista. O território relacional contém as conflitualidades dos dois primeiros territórios, enquanto os territórios imateriais possuem os conflitos de todos os outros territórios. $O$ autor defende que o território propriedade apresenta disputas internas e externas, nesse caso, tecidas com o território governança.

O território relacional porta os conflitos entre o território propriedade e governança, enquanto o território imaterial representa disputas de concepções na construção do espaço. Entendemos que o território governança é um monolítico, invisibiliza os conflitos intra/interpoderes estatais. Há disputas entre municípios, estados federados e entre Estados nacionais, comuns, por exemplo, nas guerras de lugares, dado as isenções fiscais para atração de empresas multinacionais. A concepção de território relacional é questionável, visto que separa o que é imprescindível a todo território, o campo de forças entre classes. Também não há disputas que não comportem concepções e visões de mundo diferentes.

Fernandes (2008b), com sua tipologia, separa o que muitas vezes compõe elementos de toda disputa territorial. Nos ditos "territórios propriedade não capitalista" as disputas também são internas. A título de exemplo, na produção espacial dos assentamentos, há disputas que criam cisões, dissidências, pela tessitura das linhas, dos pontos, pela produção espacial que permite determinados usos. Almeida (2006), no estudo de Assentamentos no Mato Grosso do Sul, destaca a disputa entre a lógica de produção espacial do "quadrado burro" do INCRA, do espaço coletivo em moldes leninistas do MST e a lógica do sítio, dos camponeses que compõem a base do movimento.

Por isso, a afirmação de territórios não capitalistas no interior do capitalismo pode incorrer no marxismo positivista/evolucionista, com repetição da tese do campesinato como resquício de modos de produção anteriores. Toma-se a forma da relação social não capitalista sem levar em conta a contradição, que a vincula à reprodução ampliada do capital. Portanto, no ensejo de superação do capitalismo, a relação social não capitalista torna-se território, que nega e torna-se independente do capitalismo. Na nossa compreensão os camponeses possuem espaços subordinados ao capitalismo, não porções espaciais autônomas.

Em vista disso, também suscitam indagações os territórios do campesinato, das multinacionais e do agronegócio. Se poder é sinônimo de relação social, implica também estabelecer limites, controles espaciais (SILVA, 2013). No caso em tela, se as classes denotam poder, disputam entre si a forma de ordenação e organização do espaço material. Portanto, interessa no estudo do território saber quem domina quem. Mas se o território é do campesinato, até que ponto se justifica o uso da categoria? Porque o que indagamos é que essa compreensão implica dizer, que no conjunto das relações sociais os camponeses conseguem conformar limites, controles, usos, apropriações etc.

Com isso, determinam o arranjo, a organização do espaço conforme seus objetivos. Nessa situação, não há disputa, consequentemente, não existe ameaça,

Estudos Geográficos, Rio Claro, 17: 56-77, jan./jun. 2019 (ISSN 1678-698X) http://www.periodicos.rc.biblioteca.unesp.br/index.php/estgeo 
imposição, coerção, privação, exploração, restrição de uso, apropriação da renda da terra pelo capital, mas o espaço material ordenado pelo campesinato. Nesse sentido, entendemos as razões da adjetivação, entretanto, chamamos a atenção para os riscos assumidos por tal classificação. Oliveira (1995) não adere às tipologias na definição de território. Ele entende que o território é configurado pelas relações sociais estabelecidas por três classes fundamentais: burguesia, proprietários de terra e proletariado. O território é a unidade dialética espacial que as classes criam, num processo de construção, de destruição, de manutenção e de transformação do espaço. No campo, a industrialização da agricultura concede aos capitalistas a apropriação da renda da terra, por meio da territorialização do capital e, contraditoriamente, permite a expansão da agricultura camponesa, com a subordinação e a monopolização da produção camponesa. Segundo ele:

[...] o território deve ser apreendido como síntese contraditória, como totalidade concreta do processo/modo de produção/distribuição/circulação/consumo e suas articulações e mediações supraestruturais (políticas, ideológicas, simbólicas, etc.) onde o Estado desempenha a função fundamental de regulação. É, pois, produto concreto da luta de classes travada pela sociedade no processo de produção de sua existência. [...] o território não é um prius ou um a priori, mas a contínua luta da sociedade pela socialização igualmente contínua da natureza. (OLIVEIRA, 1995, p. 26-27).

O substancial nessa definição são as relações de classe, que promovem a produção do espaço material. Infere-se que tais relações de enfrentamento, de luta de classes, conferem dimensão espacial ao território, assim como fornece sua característica sui generis. Há um território no espaço, dado pelo campo de forças entre classes, que busca manter ou destruir a organização espacial dada. Dessa forma, o autor aponta que o território é produto da luta de classes, luta que comporta dimensão concreta. Entende-se que o fundamental na abordagem territorial não é a forma em si, mas o conteúdo, as relações de poder que a explicam.

Parafraseando Oliveira (1995), o essencial é a contínua luta das classes, que imprime a contínua destruição/produção do espaço material. Os camponeses ocupam, acampam, manifestam e expressam desacordo com a organização do espaço construído. Erguem-se contra as cercas do latifúndio, da monocultura, disputam nova organização do espaço que implica destruição da organização espacial do agronegócio. Os camponeses também portam imagens espaciais convergentes, que possibilita coalizões, pactos, alianças. Tais imagens resultam de contextos político-econômicos, culturais. No campo de forças, constroem espaços precários, submetidos à força bárbara do processo de mundialização do capital.

Do mesmo modo, os povos indígenas retomam seus antigos territórios originários. Ocupam, acampam nas praças em nome do direito de ser/existir no espaço tempo. As políticas neoliberais agravam os processos de expulsão e exploração. A luta pela permanência, pela entrada na terra é cotidiana, dado que camponeses e povos indígenas são subjugados. A existência da cerca do sítio, do território originário não cerca os vetores de ação das corporações, do Estado etc., que levam para o interior desses espaços suas verdadeiras intenções. Os pacotes de insumos, a integração, as taxas de juros, as normas, a precária representação política institucional e a ausência de infraestruturas demonstram o poder de controle

Estudos Geográficos, Rio Claro, 17: 56-77, jan./jun. $2019 \quad$ (ISSN 1678-698X) http://www.periodicos.rc.biblioteca.unesp.br/index.php/estgeo 
e a quem serve majoritariamente o espaço de reprodução social do campesinato e os "territórios" originários dos povos indígenas. O acontecer hierárquico instala no campo verticalidades, as redes comandadas pelas corporações regulam o espaço, e as contradições se instalam.

$\mathrm{Na}$ correlação de forças, o espaço é submetido a um constante fazer-se. Sua produção favorável ao campesinato, ou aos povos indígenas depende da formação de classe e da coalizão horizontal negociada com outros grupos sociais explorados. Portanto, o espaço não é absoluto, imutável, pode ser reconstruído pela disputa territorial, uma vez que o capital não pode tudo, ocorrem revanches dos sujeitos do espaço banal, ligados pelas horizontalidades (SANTOS, 1994). Há potencialidades para construção do território camponês e indígena autônomos, dependente da correlação de forças, do fazer-se da classe, das disputas territoriais insurgentes, das alianças com outras classes. Para tanto, deve-se atentar para a formação da classe para si, o que implica discutir os momentos da consciência política, bem como o desenvolvimento das forças materiais de produção.

Como destaca Gramsci (2010), é importante mostrar os pontos de menor resistência e de maior força, observar o nível de organização e predisposição da força social que se defende, e analisar a situação de conjuntura ${ }^{3}$, tendo em vista a construção do território camponês/proletário/indígena liberto. Assim sendo, na abordagem territorial do Cerrado, é importante a atenção com as forças em jogo, os arcos de poder construídos, suas intencionalidades, estratagemas e ideologias (CHAVEIRO \& CALAÇA, 2012). Propõem os autores: é relevante considerar os usos e ocupações, os pactos, as dissidências, as diferenças espaço/tempo, as relações escalares, os conflitos, a dilaceração do sujeito, a ação dos invisibilizados, a reinvenção do Cerrado pela modernização.

O território é um campo de forças entre classes com dimensão espacial. Expressa-se nas ocupações, nas retomadas, nos acampamentos, nas manifestações, na resistência passiva camponesa do gado mestiço, da policultura, da indústria doméstica, da semente crioula, do adubo de origem vegetal e animal, das relações de ajuda mútua, na geografia do campesinato contrária à geografia do agronegócio. Frente às questões postas, a atenção verte-se para as classes em disputa, manifestada no espaço material. Se o território é a combinação de espaço e poder, a aparência, a forma concreta em si não é o território. Desvendá-lo implica a análise do conteúdo das forças em disputa, os enfrentamentos, conflitos, em suma, as relações sociais interpretadas sobre o prisma da política.

Deve-se atentar para os limites, os usos, as apropriações, as imagens etc., assim como para os corpos subversivos, com suas indumentárias, seus símbolos de resistência. A forma empiriza relações de domínio, exploração, sujeição, cercamento do campesinato, dos povos originários, das comunidades quilombolas. Tal qual também evidencia projetos contra hegemônicos camponeses e indígenas em disputa pela tessitura do espaço. As formas capitalistas são duradouras, as formas camponesas e indígenas são subversivas, efêmeras, transitórias, diminutas, expressões do contra espaço. A ditadura do aparente, da fixidez escamoteia novos usos, apropriações, relações escalares, pactos e dissidências, nega novos mundos em construção. A prisão à forma duradoura pode esconder territórios dissidentes, tornar inerte o que é dinâmico e mutável.

\footnotetext{
${ }^{3}$ Frosini (2017) sustenta que Gramsci (1891-1937), entende a conjuntura como o conjunto das características imediatas e transitórias da situação econômica. Trata-se das circunstâncias que determinam o mercado num momento dado, compõem as relações sociais de força num ciclo econômico.

Estudos Geográficos, Rio Claro, 17: 56-77, jan./jun. 2019 (ISSN 1678-698X)

http://www.periodicos.rc.biblioteca.unesp.br/index.php/estgeo
} 
Por isso a forma é ponto de partida, mas não de chegada. A escala de atuação dos oprimidos e suas táticas, com resistências cotidianas grafadas no espaço, ocorrem muitas vezes em escalas reduzidas, de forma transitória (SOUZA, 2013). Os territórios dissidentes envolvem ações coletivas, emancipatórias, práticas espaciais reterritorializadoras. O que implica dizer que nos territórios dissidentes às práticas espaciais são insurgentes, visam reestruturar, reorganizar o espaço (SOUZA, 2013). As reterritorializações podem ser estritas, com apropriação e controle pela presença física, do mesmo modo, podem ser amplas, com direitos formais e prerrogativas legais da propriedade privada desafiada e regras espaciais estatais rompidas (SOUZA, 2013).

Segundo 0 autor, territórios dissidentes duradouros promovem reestruturações do espaço material, as intervenções podem ser diminutas e profundas. Neles, imagens do lugar são disputadas, circuitos econômicos alternativos instalados e redes espaciais dissidentes construídas. Geralmente, os territórios dissidentes são instáveis, explosivos, móveis, pelos confrontos com 0 Estado e com as classes hegemônicas (SOUZA, 2013). Entendemos que na Geografia Agrária devemos estar atentos a construção dos territórios dissidentes, rebeldes, em busca de outro devir. É necessário escapar do fascínio com o território hegemônico capitalista, para fortalecer modernidades alternativas em construção, elaboradas pelos subalternos; camponeses, quilombolas, povos indígenas. No próximo item a discussão vincula-se ao povo Karajá, localizado no município de Aruanã-GO.

\section{OS KARAJÁ: O INDÍGENA, O RIO, A CIDADES E O BOI}

Na pesquisa de campo no povo indígena Karajá, localizado nas margens do rio Araguaia em Aruanã, no diálogo com o cacique Raul Hawakati, que nos recebeu na Aldeia Buridina, ele relatou a origem, a história de formação seu povo. Segundo ele:

O povo Karajá morava nas profundezas do rio Berohoky, (Araguaia), e só saiam à noite para caçar e procurar comida. Em uma dessas saídas, coincidiu de amanhecer e os índios ficaram maravilhados com o que viram, mas voltaram e contaram para os outros. Decidiram que viriam para fora das águas para viver no mundo maravilhoso recém-descoberto. Todos saíram pela passagem que era um buraco no leito do rio, mas um que era mais gordo, não conseguiu passar pelo buraco, ficando nas profundezas do Berohoky.

O povo Karajá pertence ao grupo Macro Jê, habitavam e ainda habitam o médio e o alto Araguaia, divididos em três grupos distintos. No médio Araguaia temos os Karajá Xambioá na região de Garimpinho, Pau D'Arco e Xambioá. No Mato Grosso, na ilha do Bananal e nas cercanias de Aruanã, região do Alto Araguaia, há os Karajá. No braço direito da Ilha da Bananal, no rio Javaé, habitam os Karajá Javaé. Moreira \& Cardoso (2003), sustentadas na entrevista concedida por Raul Hawakati, relatam a formação da aldeia Burundina, em Aruanã:

Veio um dos meus bisavô né, que veio para cá, [Aldeia Burundina]. Porque disse que lá os Karajá, até hoje acredita que tem feiticeiro

Estudos Geográficos, Rio Claro, 17: 56-77, jan./jun. 2019 (ISSN 1678-698X) http://www.periodicos.rc.biblioteca.unesp.br/index.php/estgeo 
que faz o mal, a pessoa que mexe com raizada. Ele já visado como feiticeiro né, que faz o mal. Então meu bisavô, mais novo, tinha capacidade de mexer com plantas medicinais e também espírito né. Aí quando uma criança adoecia jogava a culpa nele. Chegava até a agredir ele assim fisicamente. Aí com o tempo ele desgostou e veio embora. Naquele tempo da llha do Bananal até chegar a Aruanã tinha várias, acho que mais de 10 aldeias. Aí diz que ele chegava na aldeia o pessoal só convidava ele assim para almoçar ou jantar. Mas ninguém [convidava] ele para morar né. Aí como ele tinha sofrido muito na aldeia grande, ele não ia se oferecer porque tinha medo de sofrer agressão de novo. Aí ele veio subindo rio acima até chegar aqui no Aruanã. Ele achou o lugar muito bonito, não tinha ninguém e fez a cabaninha dele. Agora o que diz que deixou ele surpreso, foi que de um ano pro outro formou uma das maior aldeia Karajá da história. Assim formou a aldeia de Aruanã. (Raul apud Moreira \& Cardoso. 2003, p. 29).

Conforme o interlocutor seu bisavô era mal interpretado, devido ao conhecimento empírico das plantas do Cerrado. Para sobreviver se afastou do grupo, procurou um local onde pudesse viver sem perseguição, fixando residência na região do encontro das águas do rio Vermelho com o rio Araguaia. O referido lugar logo sofreu as implicações da invasão do branco, com apropriação do espaço material de reprodução social do povo indígena Karajá. Segundo o entrevistado, ele não tem uma data precisa de quando os indígenas tiveram seu primeiro contato com o branco. Mas se recorda que seus antepassados falavam de duas aldeias muito populosas, uma em Britânia nas margens do lago dos Tigres, outra no encontro do rio Vermelho com o rio Araguaia.

No século XIX, Couto Magalhães trouxe um barco a vapor para navegar de Barra do Garças até Belém do Pará. Em 1849, uma lei do império criou à aldeia Karajá e o presídio Leopoldina. O presidio foi destruído pelos Karajás, sendo reconstruído três anos depois, local onde se formou um povoado. Com a criação da Comarca do Araguaia em julho de 1875, o povoado logo evoluiu para distrito, com o nome de Santa Leopoldina. No trabalho de campo na Aldeia Buridina esses aspectos aparecem na fala do Cacique Raul. Segundo ele a construção do Presidio Leopoldina, do Colégio Princesa Imperial Dona Isabel e do Porto Manoel Pinto tinham a intenção de escravizar o indígena Karajás, destruir sua cultura e torna-lo mão-de-obra barata. Essas infraestruturas tinham vínculo com o ideário da ilhaBrasil e a apropriação das terras indígenas, com o discurso de civilização do sertão e modernização do território (CARDOSO, 2015).

Cardoso (2015) relata que Couto de Magalhães estabeleceu no século XIX o Colégio, com o fim de ensinar a língua portuguesa as crianças Karajás, para que essas se tornassem "os línguas", os difusores da língua entre eles. Esse processo de assimilação foi acompanhado pelo extermínio das doenças. O cacique Raul mencionou que em 1947 as aldeias tinham cerca de mil indígenas, o surto de Sarampo provocou a redução para quatro sobreviventes, seja pela morte ou migração por medo dessa endemia, assim em 1967 a aldeia contava com oito casais. A difusão de doenças foi um viés utilizado para a apropriação dos territórios indígenas no Brasil, (ARAUJO, 2015). Segundo o cacique, mesmo assim um pequeno grupo de indígenas se recusou a sair e agruparam-se em uma estrita faixa de terras na margem direita do rio Araguaia, onde se encontravam sepultados seus ancestrais, ali resistindo as investidas do branco invasor.

Estudos Geográficos, Rio Claro, 17: 56-77, jan./jun. $2019 \quad$ (ISSN 1678-698X) http://www.periodicos.rc.biblioteca.unesp.br/index.php/estgeo 
Segundo Moreira e Cardoso (2003), na década de 1970, com a expansão da cidade de Aruanã, a prefeitura destruiu o cemitério e jogou as ossadas dos antepassados indígenas no rio. Os Karajás mais uma vez foram vítimas do desrespeito, do descaso e da exploração. As perseguições não terminaram, o poder público tomou posse de terras Karajás para edificação da praça Almirante Barroso e do Colégio Dom Cândido Penso e para construção da estação de tratamento de água e esgoto. Com continuas denúncias de grilagem das terras Karajás, a Fundação Nacional do índio-FUNAl entrou com um mandado de segurança e obteve a desapropriação da fazenda Aricá, localizada na margem esquerda do rio Araguaia, no estado de Mato Grosso. No início do século XXI foi realizado a homologação definitiva dessa área, marco da resistência da cultura e da etnia Karajá do rio Berohoky.

Mas o confinamento dos Karajás na aldeia Burundina, com a mobilidade das fronteiras foi também propiciado pela frente de expansão pecuária. Segundo o cacique Raul, com as grandes fazendas e o desmatamento houve a destruição do modo de vida Karajás. A relação metabólica com o Cerrado para a extração de frutos, para a caça de animais ou para o fornecimento de madeira foi afetada. A piscicultura predatória afetou a disponibilidade de peixes. Portanto, negou-se o direito ao território aos Karajás (CARDOSO, 2015). Em detrimento, se fortaleceu o colonialismo interno com os coronéis modernizados, por meio do mandonismo rural (BOSI, 1992). O uso do Rio Araguaia pelo turismo, também tem acarretado em domínio do território Karajás. Segundo o cacique, eles são do fundo do rio. A identidade territorial Karajás tem o rio Araguaia como elemento simbólico, no entanto, esse rio tem sido apropriado pelos turistas em Aruanã.

Elias (2015) destaca que na temporada de 2015 visitaram Aruanã cerca de oitocentas pessoas. Esses sujeitos transportam para o rio suas práticas socioespaciais narcisistas e hedonistas. Corpos malhados desfilam pelas margens ou em performances sobre carros. Lanchas, barcos e outros meios de transporte aquático percorrem as águas num constante vaivém. A representação de Aruanã como a "praia do Cerrado", com a transposição da vida urbana metropolitana para ela causa aumento da prostituição e do alcoolismo. O território Karajás é apropriado pelas pousadas e pelos condomínios fechados.

A divisão territorial do trabalho, com a especialização produtiva do município de Aruanã na pecuária e da atividade turística, tem efeitos nefastos para o território Karajá. Raul luta para fortalecer a cultura, com a defesa da oralidade, da memória, do respeito aos ensinamentos dos antepassados e a conservação da língua. Também enfrenta dificuldades pelo descrédito com a história dos antepassados, pelos casamentos mistos, que fazem com que não índios insiram na aldeia suas territorialidades capitalistas, como a construção de cercas em volta da residência (Foto 1).

Do mesmo modo, a FUNAI tutela e busca realizar a incorporação civilizada do indígena a nação, (CARDOSO, 2015). O cacique reclama que essa fundação admite membros que não entendem da questão indígena. A escola indígena bilíngue representou uma resistência. Segundo o cacique, aprender a língua portuguesa permite aos Karajás ter seus próprios representantes. Trata-se da consciência de que a cultura se transmite pela educação, em que se reafirma a consciência de grupo, de projeto (BOSI, 1992). O cacique prega a necessidade de elaboração de projetos de ecoturismo.

Estudos Geográficos, Rio Claro, 17: 56-77, jan./jun. $2019 \quad$ (ISSN 1678-698X) http://www.periodicos.rc.biblioteca.unesp.br/index.php/estgeo 


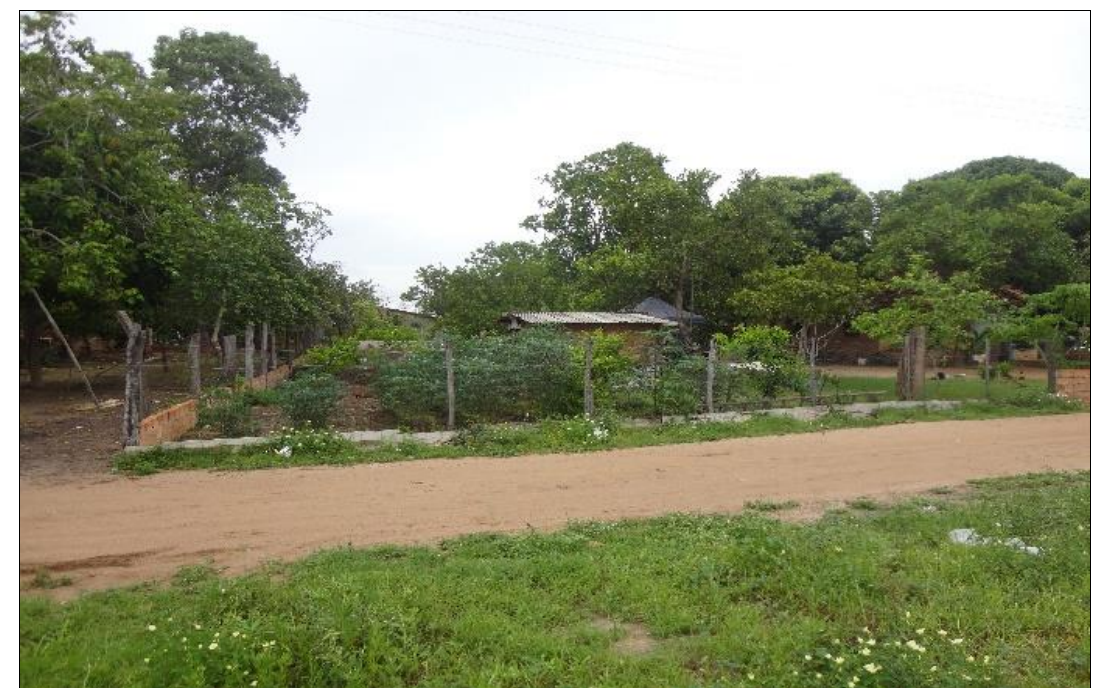

Figura 1 - Cerca construída no interior da Aldeia Buridina

Fonte: Trabalho de Campo, fev. de 2015.

Autor: SILVA, E. B. 2015.

Também é o responsável pelo Museu Karajás, fonte de renda pela venda do artesanato e, contraditoriamente, de mercantilização da cultura Karajá. $\mathrm{Na}$ observação da paisagem de Buridina, a cerca que circunda a aldeia revela o confinamento, o que restou do antigo território apropriado pelas fazendas e pela urbanização. Nela a presença de objetos que conectam com as redes de comunicação e consumo, que difundem a ideologia capitalista e capturam a psicosfera, demonstra que a mundialização do capital penetrou no povo Karajá. As formas vinculam esse espaço a divisão territorial do trabalho. Os Karajás não escapam a totalidade do diabo (SANTOS, 2003). Não obstante, além da violência do capital, há a colonialidade do poder das missões religiosas, que entende o indígena como raça inferior que deve ser domesticado, (CARDOSO, 2015). Na foto 2 nota-se a ação da Igreja Batista na aldeia Burundina.

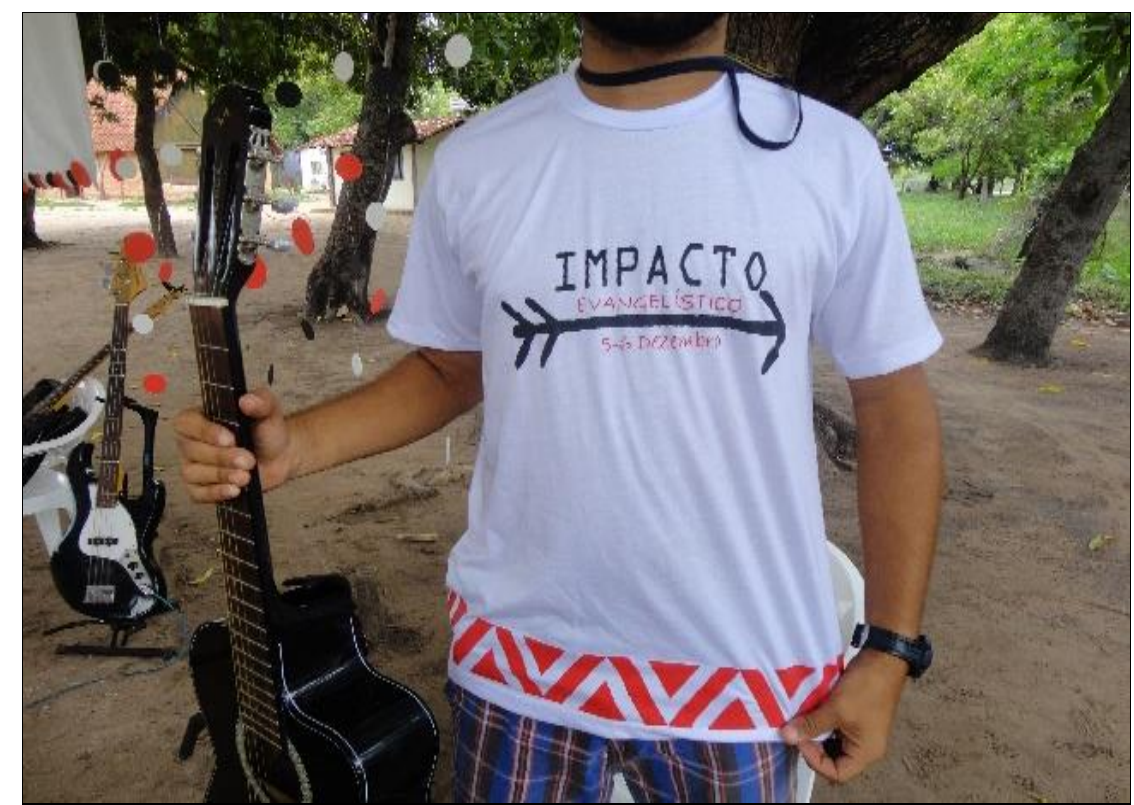

Figura 2 - Ação missionária da Igreja Batista no Povo Karajás Fonte: Trabalho de Campo Realizado em fev. de 2019. Autor: SILVA, E. B. 2019.

Estudos Geográficos, Rio Claro, 17: 56-77, jan./jun. 2019 (ISSN 1678-698X) http://www.periodicos.rc.biblioteca.unesp.br/index.php/estgeo 
Na camiseta se observa a reedição da estratégia jesuítica, em que no seu slogan se lê: "impacto evangelístico." Quijano (2004) entende que há na América Latina um traço racial/patriarcal, hierárquico e escravista nas relações sociais. Leite \& Santos (2010) afirmam que a morte no Cerrado e do Cerrado inviabiliza a identidade social dos grupos originários. Moreira (2012) compreende que na divisão territorial do trabalho, o Cerrado tem seu arranjo determinado pelos complexos agroindustriais. Goiás se moderniza com as agroindústrias, com a divisão do trabalho intra-agricola, com o surgimento de atividades terciarias e secundarias, com a urbanização.

Mas o neoliberalismo promove um desmonte do projeto estatal de integração nacional pós-1930, cria-se um desencaixe, um lugar desorganico, pela privatização da gestão do espaço. Os Karajás não escaparam a escravização, a lógica racial hierárquica colonialista da sociedade latino-americana. A existência deles foi afetada pela apropriação do Cerrado e do Rio Araguaia pela modernização da pecuária, pela urbanização e pelo turismo, respectivamente. Atualmente a produção de carne no latifúndio modernizado em Aruanã, articulado em escala internacional com o capitalismo mundializado e laços débeis com a economia local traz à tona a importância da rede política de resistência. O isolamento representa a eliminação, urge tecer alianças dissidentes em diferentes escalas com outros grupos explorados, para obter conquistas negociadas.

\section{CONSIDERAÇÕES FINAIS}

Há uma condição ontológica do território. A observação desse pressuposto não nos exime de cuidados quanto ao uso desta categoria nas pesquisas em Geografia e em geografia agrária. Raffestin (1993), por exemplo, com o conceito de ator, parece querer escapar do debate da classe social. Seu uso em estudos do campesinato, entendido como classe social, merece explicação e atenção do pesquisador. Há outros pressupostos importantes, como a advertência de Saquet (2011) de observação das temporalidades lentas. Esse geógrafo brasileiro, entretanto, apesar de se propor elaborar uma proposta de abordagem territorial operativa politicamente, demonstra dificuldades nesse empreendimento.

Faz uso indistinto dos termos sujeito e ator, grupo e classe social, assim como defende a observação de vinte e oito leis na abordagem territorial. Sua proposta é ampla, confusa e ancorada no ecletismo metodológico, com aportes do marxismo, do estruturalismo e do anarquismo. Haesbaert (2004), Silva (2013) e Bañuelos \& Bórques et. al (2015) oferecem instrumentos analíticos para as pesquisas das identidades territoriais, do território como criação, significação imaginária social, ou como parte do corpo dos sujeitos, como sinônimo de terra. Em contraposição, Fernandes (1999 \& 2008), na sua proposta tipológica, separa o que compõe toda disputa territorial.

Sua compreensão suscita questionamentos: o que o autor quer dizer com territórios não capitalistas? Não está claro o nível de controle e domínio dos camponeses sobre suas propriedades e sobre a produção realizada? Se quer afirmar que os camponeses são autônomos do sistema capitalista? $\mathrm{E}$ a subordinação camponesa? $\mathrm{E}$ a reprodução funcional do campesinato no capitalismo? Questões que precisam ser refletidas em propostas que defendem a adjetivação: território do campesinato. Para nós o território é um campo de forças entre classes com dimensão espacial. As classes disputam imagens, usos,

Estudos Geográficos, Rio Claro, 17: 56-77, jan./jun. $2019 \quad$ (ISSN 1678-698X) http://www.periodicos.rc.biblioteca.unesp.br/index.php/estgeo 
apropriações, limites na produção do espaço material. O espaço compõe os sujeitos sociais, eles carregam suas geo-grafias, que comparecem nas disputas territoriais e na tessitura do espaço.

Entendemos, do mesmo modo, que muitos pesquisadores aprisionam-se nas formas duradouras, cristalizadas, hegemônicas, em prejuízo das formas efêmeras, instáveis, emancipatórias, transitórias, construídas nas pequenas escalas. Nesse ínterim, os Karajás, historicamente mantiveram um campo de forças com os agentes do colonialismo e da colonialidade do poder, representados pelas missões religiosas católicas e protestantes, pelos fazendeiros, pelos agentes da especulação imobiliária e do turismo.

A correlação de forças desigual implicou redução drástica do seu território originário. Os residentes na aldeia Burundina estão confinados num espaço diminuto, acossados pelos agentes capitalistas e pela psicosfera do capital. Seria exagero afirmar, parafraseando Haesbaert (2004), que os Karajás da aldeia Burundina encontram "desterritorializados" na imobilidade? Esta provocação tem o intuito de deixar o debate aberto, sobre as possibilidades do uso da categoria território para o desenvolvimento de pesquisas em geografia agrária.

\section{REFERÊNCIAS}

ARAÚJO, Gilvan C. C. de. A ocupação do território: a fé católica e as primeiras bandeiras. In: Do ufanismo edênico ao saudosismo heroico: ideologia e discurso geográfico nacional brasileiro. Jundiaí: Paco editorial, 2015, p. 67-96.

BAÑUELOS, Patricia Couturier; BÓRQUEZ, Luciano Concheiro et. al. Tecnologias de mineração que tentam contra a Mãe-Terra: subsunción formal e real dos territórios ao capital. Revista Geonordeste, São Cristovão, ano XXVI, no 1, p. 197214. Jan./jul. 2015. Disponível em: seer.ufs.br/index.php. Acesso em: 24 de out. de 2017.

BONNEMAIZON, Joel. Viagem em torno do território. In: CORRÊA, Roberto Lobato; ROSENDAHL, Zeni (orgs.). Geografia Cultural: um século (3). Rio de Janeiro: EDUERJ, 2002. p. 83-131.

BOSI, Alfredo. Colônia, culto e Cultura. In:

A dialética da colonização. São Paulo: Companhia das letras, 1992. p. 11-25.

CALAÇA, Manoel; CHAVEIRO, Eguimar Felício. Por uma abordagem territorial do Cerrado goiano. In: CANDIOTTO, Luciano Zanetti Pessôa; SAQUET, Marcos Aurélio (orgs.). Geografia da e para a cooperação ao desenvolvimento territorial: experiências brasileiras e italianas. São Paulo: Outras Expressões, 2012. 191-206 p.

CARDOSO, Ludmilla Stival. A construção socioterritorial do Estado-nação brasileiro. In: _. De Calibán a próspero: a sociedade brasileira e a política externa da república (1889-1945). 2015. 237 p. Tese de doutorado. Programa de Pósgraduação em História. Goiânia, 2015. P. 86-154.

Estudos Geográficos, Rio Claro, 17: 56-77, jan./jun. 2019 (ISSN 1678-698X) http://www.periodicos.rc.biblioteca.unesp.br/index.php/estgeo 
COSTA, Wanderley M. da. A geografia política clássica. In: Geografia política e geopolítica: discursos sobre o território e o poder. 2 ed. São Paulo: Edusp, 2008, p. 31-54.

ELIAS, Gilmar. A Serra Dourada e a Planície do Araguaia. Goiânia: UFG, 04 dez. 2015. Palestra ministrada aos estudantes de pós-graduação em geografia da UFG.

ENGELS, Friederich. O papel da mão na transformação do macaco em homem. (Tradução José Braz). São Paulo: O Vermelho, Neue Zeit (1876]2004). Disponível em: https://www.marxists.org/portugues/marx. Acesso em: 23 de set. de 2017.

FERNANDES, Bernardo Mançano. Movimentos socioterritoriais e movimentos socioespaciais: contribuição teórica para uma leitura geográfica dos movimentos sociais. In: Revista Nera, Presidente Prudente, v.08, n. 06, p. 14-34, jan/jun 2005.

Questão agrária: conflitualidade e desenvolvimento territorial. In: BUAINAIN, Antonio M. (ed.). Luta pela Terra, Reforma Agrária e Gestão de Conflitos no Brasil. Campinas: Editora da Unicamp, 2008a, p. 173-224.

Sobre a tipologia de territórios. In: SAQUET, Marcos A.; SPOSITO, Eliseu S. (orgs.). Território e territorialidades: teorias, processos e conflitos. São Paulo: Expressão Popular, UNESP, 2008b, p. 197-216.

FOUCAULT, Michel. Microfísica do poder. Rio de Janeiro: Edições Graal, 1979.

FROSINI, Fabio. Conjuntura. In: LIGUORI, Guido; VOZA, Pasquale. Dicionário Gramasciano. (Tradução de Ana Maria Chiarini, Diego Silveira Coelho Ferreira, Leandro de Oliveira Galastri, Silvia de Bernardinis). São Paulo: Boitempo, 2017. p. 139.

GOMES, Paulo C. da Costa. Sobre territórios, escalas, e responsabilidade. In: HEIDRICH, Álvaro Luiz; COSTA, Benhur Pinós da; PIRES, Claudia Luísa Z.; UEDA, Vanda. (orgs.). A emergência da multiterritorialidade: A ressignificação da relação do humano com o espaço. Canoas: Editora Ulbra; Porto Alegre: Editora da UFRGS, 2008. 37-46 p.

A dimensão ontológica do território no debate da cidadania: o exemplo canadense. Território, Rio de Janeiro, v.01, n. 02, p. 43-62, jan./jun. 1997.

GOTMANN, Jean. A evolução do conceito de território. In: Boletim Campineiro de Geografia, v. 02, n. 03, p. 523-545, 2012.

GRAMSCI, Antônio. Análise das situações: correlações de forças. 2010, 7 p. Disponível em: http: www.fundaçãolaurocampos.org.br Acesso em: 10 jan. 2016.

HAESBAERT, Rogério. O mito da desterritorialização: do fim dos territórios à multiterritorialidade. RJ: Bertrand Brasil, 2004. 391 p.

Estudos Geográficos, Rio Claro, 17: 56-77, jan./jun. 2019 (ISSN 1678-698X) http://www.periodicos.rc.biblioteca.unesp.br/index.php/estgeo 
MARX, Karl. As teses sobre Feuerbach (1845). (Tradução de Nélson Jahr Garcia). São Paulo: Ridendo Castigat Mores, 1999. 9 p. Disponível em: www.jahr.org. Acesso em: 9 jan. 2016.

MOREIRA, Alexandra Patrícia \& CARDOSO, Lenice Maria. Cultura e aculturação dos Karajá de Aruanã. Monografia apresentada como requisito à conclusão do Curso de Licenciatura Plena em História da Universidade Estadual de Goiás, Unidade Universitária de Itapuranga. 2003.

MOREIRA, Ruy. A nova divisão territorial do trabalho e as tendências de configuração do espaço brasileiro. In: Formação espacial brasileira: uma contribuição crítica à geografia do Brasil. Rio de Janeiro: Consequência, 2012. p. 245-276.

OLIVEIRA, Ariovaldo Umbelino de. Geografia e Território: desenvolvimento e contradições na agricultura. In: Boletim de Geografia Teorética, v. 25, n. 49-50, p.15-58, 1995.

QUIJANO, Anibal. El movimento indígena y las questiones pendientes em América Latina. Política externa, São Paulo, v. 12, № 04 marc. /abr. 2004, p. 77-97.

RAFFESTIN, Claude. Por uma geografia do poder. São Paulo: Ática, 1993. 266 p.

RATZEL, Friedrich. As leis de crescimento espacial dos Estados. In: MORAES, Antônio Carlos R. (org.). Ratzel. São Paulo: Ática, 1990, p. 175-192.

El território, la sociedade e el estado. In: MENDOZA, Josefina G.; JIMÉNES, Julio M.; CANTERO, Nicolas O. (orgs.). El pensamento geográfico. Estudio interpretativo y antología de textos (De Humboldt a las tendencias radicales). 2 ed. Barcelona: Alianza Editorial, 1988, p. 193-203.

SANTOS, Milton. O retorno do território. In: SANTOS, M.; SOUZA, Adélia A. de; SILVEIRA, Maria Laura (orgs.). Território -globalização e fragmentação. São Paulo: Hucitec, 1994, p. 15-20.

A totalidade do diabo: como as formas geográficas difundem o capital e $\overline{\text { mudam }}$ as estruturas sociais. In: Economia espacial. São Paulo: HUCITEC, 2003. p.187-202.

SAQUET, Marcos Aurélio. Por uma geografia das territorialidades e das temporalidades: Uma concepção multidimensional voltada para a cooperação e para o desenvolvimento territorial. São Paulo: Outras expressões, 2011. 123 p.

Por uma geografia das territorialidades e das temporalidades: uma concepção multidimensional voltada para a cooperação e para o desenvolvimento territorial. $2^{\underline{a}}$ edição revisada e ampliada. Rio de Janeiro: Consequência, 2015. 162 p.

Estudos Geográficos, Rio Claro, 17: 56-77, jan./jun. 2019 (ISSN 1678-698X) http://www.periodicos.rc.biblioteca.unesp.br/index.php/estgeo 
SILVA, Ana Cristina. Território e significações imaginárias no pensamento geográfico brasileiro. Goiânia: Cegraf, 2013. 318 p.

SOUZA, Marcelo José Lopes de. O território: sobre espaço e poder, autonomia e desenvolvimento. In: CASTRO, Iná Elias; CORREA, Roberto Lobato et al. (orgs.). Geografia: conceitos e temas. Rio de Janeiro: Bertrand Brasil, 1995. 78-116 p.

Território e (des) territorialização. In: Os conceitos fundamentais da pesquisa sócio-espacial. Rio de Janeiro: Bertrand Brasil, 2013, p. 77-110.

WAUTIER, Anne Marie. Do Ator ao Sujeito: ainda existe um lugar para uma ação coletiva pelo trabalho? Contexto e Educação, Unijuí, ano 16, no 63, p. 35-56, jul./set. de 2001.

WOLF, Eric R. Las Luchas Campesinas del Siglo XX. (Tradução de Emilio Rubin). Madrid: Siglo Veintiuno de España Editores, sa, 1972. 438 p. 